Minister's visit gives boost to UK/South Africa science links

Cape Town. As part of a move to strengthen renewed scientific links between Britain and South Africa, Ben Ngubane, South Africa's Minister of Arts, Culture, Science and Technology, has been invited by the British government to deliver the third Zuckerman Memorial Lecture in London in October.

The lectures are named after Solly (later Lord) Zuckerman, the Cape Town-born zoologist who went to the University of Oxford in 1934, and later rose to become chief scientific adviser to the British government (1960-66).

The invitation came at the end of a visit to South Africa last week by a Ngubane: to give British delegation London lecture. headed by David

Hunt, the science minister, which included meetings on biomedical science at the University of Cape Town and on agricultural research at the University of Stellenbosch.

Describing biotechnology as the key to the dual challenge facing South African agriculture - namely meeting the requirements of both national planning and the abolition of trade tariffs required by General Agreement on Tariffs and Trade Sakkie Pretorius, professor of microbiology at Stellenbosch, said that "co-operative research with Britain could help us significantly".

Hunt's visit has been widely welcomed in the scientific community. Friedel Sellschop, co-chairman of Ngubane's advisory committee, emphasized its particular significance for South Africa's planned 'technology foresight' exercise. This will be conducted with British assistance, and a South African representative will be seconded to the Office of Science and Technology in London to participate in an assessment of the current British technology foresight exercise.

South African scientists are also enthusiastic about the decision of the two governments to set up of a modest fund to finance joint projects between research teams in the their respective countries. But they warn that the money needs to be used carefully. "If properly used, this money should unlock other sources of funding", says Sellschop. "But very careful consideration should be given as to how it is spent. In particular, small-scale projects should be encouraged."

\title{
University blocks efforts to reveal researchers' identity
}

San Francisco. The University of California has successfully resisted demands that it should reveal the identity of scholars researching library documents on the health effects of smoking that are claimed to have been stolen.

The ruling was made last week by a Superior Court in San Francisco as part of a battle between the university and the tobacco company Brown \& Williamson over ownership of the papers. The documents suggest that the company concealed data for decades about the addictive nature of smoking.

"B\&W's panic regarding the documents is not surprising," UC attorneys wrote in a memorandum to the court in February. They described the contents of the documents as of "immense public and academic importance to smoking and public health and the history of tobacco regulation".

But the company claims they contain confidential client-attorney communications, as well as attornies' notes and sensitive trade secrets. It says that some of the documents were improperly released by a congressional subcommittee, and that others were stolen by an assistant paralegal who had worked on a project for the company.

The materials were sent anonymously to Stanton Glantz, a professor of medicine at the University of California who is an expert on smoking and public health. He passed them to the library and put together a team of researchers to study the material - a project that the university told the court was critical to academic and public knowledge.

Brown \& Williamson has now asked the court to instruct the university to return the papers. It also wants the university to release library records that would show who had provided the documents and who had studied them, arguing that it has to take steps to prevent further releases of the material.

According to the university, the company was so keen to check who consulted the documents that at one point it sent private detectives to sit outside the library archives and note everyone who entered.

The university told the court that it considered the documents were now in the public domain, and that Brown \& Williamson's conduct suggested that the company was willing to go to unacceptable extremes to stop research it believed to be unfavourable.

Glantz praised the university's efforts to defend the documents and researchers' privacy. "The University of California is taking a very principled interest in academic freedom and the public interest," he said.

UC is just one of many institutions to receive copies of the Brown \& Williamson documents. The US media has reported extensively on their contents, and they have been debated in congressional hearings. The tobacco company attempted to demand inspection of copies held by members of Congress and the media, but the US District Court for Columbia quashed the subpoenas.

In delivering an opinion on the latter case, Judge Harold $\mathrm{H}$. Greene said that the tobacco company was trying to intimidate and harass those attempting to bring to light evidence that it may have concealed knowledge that its products were both health hazards and addictive.

The San Francisco court is to hold a hearing on 17 March to resolve the issue of access to the documents. At present, this is limited to lawyers for both sides of the case.

Sally Lehrman

\section{Molecular studies centre planned for Bonn}

Munich. Science is to benefit from the post-reunification decision to reinstate Berlin as the capital of Germany. As part of a compensation programme to Bonn, the federal research ministry and the research ministry in Nordrhein-Westfalen, the regional authority (Land) that covers the city, have agreed to set up a foundation to support the creation of an ambitious new interdisciplinary research centre in the Bonn area.

The foundation will be established with DM750 million (US\$523.5 million). DM685 million will come from a federal compensation fund, and the Land intends to make up the balance. Part of the capital will be used to build new laboratories for the centre; conversion of one of the existing office buildings, many of which will be left empty when the government leaves has been ruled out on safety grounds.

The centre is to be known as the Centre of Advanced European Studies and Research (Caesar). It will avoid the lack of flexibility from which many Germany research institutes suffer by employing nearly all of its 300 scientists - who will work in 60 small groups - on limited term contracts of at most ten years.

The research groups will work on complex molecular systems that demand interdisciplinary approaches, for example neural networks or optoelectronics. The Caesar centre is intended to compete with research establishments such as the Princeton Institute for Advanced Studies in New Jersey and the Scripps Research Institute in California. A committee will be established to draw up detailed procedures in the next few weeks.

Alison Abbott 